\title{
Artificial Neural Network application to the friction welding of AISI 316 and $\mathrm{Ck} 45$ steels
}

\author{
I. Ersozlu ${ }^{1}$, S. Celik ${ }^{2 *}$ \\ ${ }^{1}$ Department of Mechanical Engineering, Army Academy, 06100, Ankara, Turkey \\ ${ }^{2}$ Department of Mechanical Engineering, Engineering Faculty, Balikesir University, 10145, Balikesir, Turkey
}

Received 2 July 2014, received in revised form 20 September 2016, accepted 11 March 2019

\begin{abstract}
The optimization of the friction welding parameters through experimental studies does not only cause loss of time and materials but also increases the cost. In this study, an Artificial Neural Network (ANN) model is developed for the analysis of the correlation between the friction welding parameters and tensile strength of both AISI 316 austenitic-stainless steel and $\mathrm{Ck} 45$ steel. The input parameters of the model are friction time, friction pressure and upset pressure while tensile strength is the output. Experimental data are used to train and test the neural network. A good correlation was obtained between the experimental values and the ANN model prediction $\left(R^{2}=0.9711\right)$. By using this model, the number of experiments to obtain optimal parameters of friction welding and number of tensile tests could be minimized.

K e y words: friction welding, AISI 316 stainless steel, Ck 45 steel, mechanical properties, Artificial Neural Network (ANN)
\end{abstract}

\section{Introduction}

Friction welding is a solid state welding process. It has been used extensively in manufacturing methods of dissimilar material combinations. Main advantages of friction welding are high material saving, low production time and the possibility of welding of dissimilar metals or alloys. In the friction welding process, heat is generated by conversion of mechanical energy into thermal energy at the interfaces of the components during rotation under pressure without any energy from the environment. Generally, the friction welding methods can be examined in two ways as continuous-drive and inertia welding [1-3].

In continuous drive friction welding, one of the specimens is held stationary, the other is rotated at a constant speed, and the stationary part is pushed towards another part under axial pressure. Therefore, the friction at the interface of the specimens converts mechanical energy to heat energy. After a specific period when the welding temperature is reached at the interface of the specimens, rotational movement is stopped, and pressure is increased. Keeping the pieces at this condition for a while completes the welding pro- cess. The most effective factors in the friction welding process are the friction time $t_{\mathrm{f}}$, friction pressure $P_{\mathrm{f}}$, upset time $t_{\mathrm{u}}$, upset pressure $P_{\mathrm{u}}$, rotational speed $n$ and the characteristic features of the welded material. The most important parameters of the welding method are shown in Fig. 1. Optimization of friction welding parameters is required to obtain good quality joints [1-4].

Materials have different chemical, physical and metallurgical properties. Some materials have high corrosion resistance, some are light, and some materials have low cost. However, sometimes combinations of various materials with various properties are required. Therefore, the joining of dissimilar materials is necessary. Joining of various combinations of different materials can lead to reduce the cost and increase efficiency. Different steels are also used in the production of the same part. The austenitic stainless steels are essentially stain and corrosion resistant. The austenitic stainless steel is preferred more than other stainless-steel types due to easiness in the welding process. Then, some negative metallurgic changes are taken into consideration in welding of the steels. These changes are given as delta ferrite phase, sigma

*Corresponding author: tel.: +90 (266) 6121194; fax: +90 (266) 6121257; e-mail address: scelik@balikesir.edu.tr 
Table 1. The chemical composition and tensile strength of the materials used in the experiments

\begin{tabular}{lccccccccc}
\hline Material & $\% \mathrm{C}$ & $\% \mathrm{P}$ & $\% \mathrm{~S}$ & $\% \mathrm{Mn}$ & $\% \mathrm{Si}$ & $\% \mathrm{Mo}$ & $\% \mathrm{Cr}$ & $\% \mathrm{Ni}$ & Tensile strength $(\mathrm{MPa})$ \\
\hline AISI 316 & 0.032 & - & 0.018 & 1.464 & 0.378 & 2.098 & 17.06 & 10.63 & 663.55 \\
Ck 45 & 0.39 & 0.026 & 0.009 & 0.646 & 0.212 & 0.033 & 0.213 & 0.113 & 715.2 \\
\hline
\end{tabular}

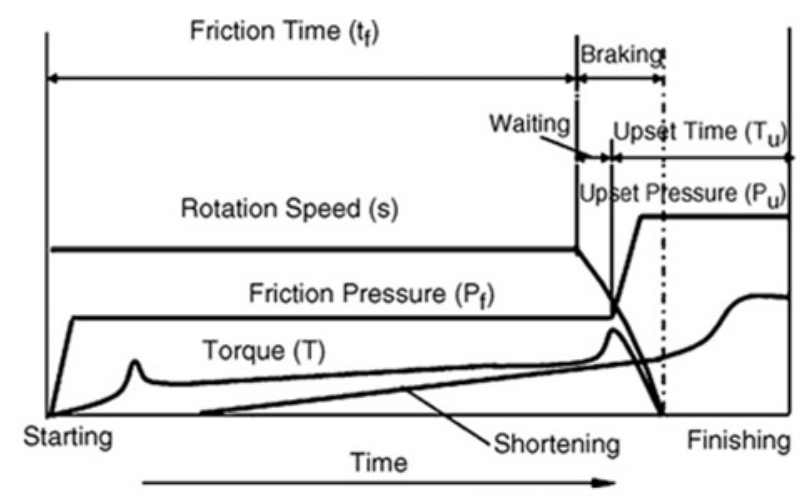

Fig. 1. Parameters of continuous drive friction welding.

phase, stress-corrosion cracking and chrome-carbide. However, the friction-welding method eliminates negative metallurgic changes because of short time and rapid cooling in working $[1,5,6]$.

Various researchers carried out different studies on friction welding. The welding strength and metallurgic properties of the joints were investigated using austenitic-stainless steel (AISI 304) [1, 7]. Özdemir et al. [8] experimentally investigated the interface properties in terms of rotational speed in friction-welded AISI 304L to AISI 4340 alloy steel. It was observed by the authors that the tensile strength increases with the rise of rotational speed. Arivazhagan et al. [9] carried out a study on the microstructure and mechanical properties of AISI 304 stainless steel and AISI 4140 low alloy steel joints by different welding methods. Domblesky and Kraft [10] tried to determine upsetting performances which are similar AA2024/AA2024, AISI 304/304 metals that combined friction welding method and which are dissimilar AISI 304/AISI 1018, AISI 1018/ETP Cu metals.

Recently, in the fields of materials science and engineering, computer-aided ANN modeling has gained increased importance. An ANN is a mathematical model consisting of some highly interconnected processing elements organized into layers, the geometry and functionality of which have been based on that of the human brain. The ANNs are parallel process elements with a mathematical model of a biological neuron. This model was developed for the analysis and simulation of the correlation between the friction stir welding parameters of aluminum plates and mechanical prop- erties. The data were obtained experimentally, and then ANN was applied [11-13]. In friction welding, the variation between theoretical and experimental values of flash features is analyzed using the ANN [14]. An artificial neural network-based model was developed to predict the laser transmission weld quality in terms of lap-shear strength and weld-seam width [15]. Most of the researchers used ANN for prediction of different process parameters for the desired outputs [1620]. To acquire welding parameters providing the best strength of the joint in combined materials with friction welding, numerous experimental studies should be conducted with different welding parameters. This situation causes loss of time, waste of materials as well as increasing the cost. If a reliable predictor model providing the strength of the joint depending on friction welding parameters is employed, the amount of experimental studies is reduced to a minimum to acquire sufficient welding strength.

Manufacturing of a water pump requires resistance to corrosion and longer operating life. It is deemed suitable to use the AISI 316 austenitic stainless steel performing high resistance to corrosion for the impeller and the Ck 45 carbon steel with the magnetic permeability for the shaft. The joining of AISI 316 stainless steel and $\mathrm{Ck} 45$ carbon steel was achieved by using the friction welding method. The welding strength was tested through the tensile test. Macroand microstructure investigations of welded samples were conducted to determine the suitable welding parameters [21]. In the present study, an artificial neural network-based model is developed to predict the friction weld quality in terms of tensile strength. The data were obtained experimentally, and then ANN application was implemented. The predicted outputs based on the ANN model are found to be in good agreement with the experimental data set.

\section{Experimental procedure}

AISI 316 austenitic-stainless steel and Ck 45 steel parts, which are $10 \mathrm{~mm}$ in diameter and $80 \mathrm{~mm}$ in length, were used in the friction welding experiments. The chemical composition and measured tensile strength of the parent materials are given in Table 1 .

A computer controlled, continuous driving friction welding set-up was used in this study [4]. Up- 
Table 2. Experimental data used to train the ANN model

\begin{tabular}{ccccc}
\hline $\begin{array}{c}\text { Specimen } \\
\text { No }\end{array}$ & $\begin{array}{c}\text { Friction time } \\
(\mathrm{s})\end{array}$ & $\begin{array}{c}\text { Friction pressure } \\
(\mathrm{MPa})\end{array}$ & $\begin{array}{c}\text { Upset pressure } \\
(\mathrm{MPa})\end{array}$ & $\begin{array}{c}\text { Tensile strength } \\
(\mathrm{MPa})\end{array}$ \\
\hline 1 & 8 & 80 & 160 & 423.5 \\
2 & 10 & 80 & 160 & 518.4 \\
3 & 10 & 80 & 200 & 659.3 \\
4 & 6 & 100 & 120 & 57.65 \\
5 & 6 & 100 & 200 & 192.9 \\
6 & 8 & 100 & 120 & 515.65 \\
7 & 8 & 100 & 200 & 580.4 \\
8 & 10 & 100 & 160 & 702.15 \\
9 & 10 & 100 & 200 & 392.55 \\
11 & 6 & 120 & 160 & 563.65 \\
12 & 6 & 120 & 200 & 256.95 \\
13 & 8 & 120 & 120 & 398.75 \\
\hline
\end{tabular}

Table 3. Experimental data used to test the ANN model

\begin{tabular}{ccccc}
\hline $\begin{array}{c}\text { Specimen } \\
\text { No }\end{array}$ & $\begin{array}{c}\text { Friction time } \\
(\mathrm{s})\end{array}$ & $\begin{array}{c}\text { Friction pressure } \\
(\mathrm{MPa})\end{array}$ & $\begin{array}{c}\text { Upset pressure } \\
(\mathrm{MPa})\end{array}$ & $\begin{array}{c}\text { Tensile strength } \\
(\mathrm{MPa})\end{array}$ \\
\hline 1 & 8 & 80 & 200 & 653.3 \\
2 & 6 & 100 & 160 & 380.95 \\
3 & 8 & 100 & 160 & 430.3 \\
4 & 10 & 100 & 120 & 277.75 \\
5 & 6 & 120 & 120 & 250.7 \\
\hline
\end{tabular}

set time $\left(t_{\mathrm{u}}\right)$ and rotational speed were fixed at 20 $\mathrm{s}$ and $3000 \mathrm{rev} \mathrm{min}^{-1}$, respectively, while the friction time $\left(t_{\mathrm{s}}\right)$, friction pressure $\left(P_{\mathrm{s}}\right)$ and upset pressure $\left(P_{\mathrm{u}}\right)$ values were alternated as given in Tables 2 and 3. The macroscopic view of welded specimens is shown in Fig. 2. Five experimental runs were carried out for each set of welding parameters. Tensile strength was measured to check the mechanical performance of the welding. The macroscopic view of the tensile tested specimen can be seen in Fig. 3. Tensile tests applied on the welded specimens revealed that friction time, friction pressure and upset pressure, which are friction welding parameters, were effective on the joint strength.

The optimum welding parameters were found to be $100 \mathrm{MPa}$ of friction pressure, $10 \mathrm{~s}$ of friction time, $200 \mathrm{MPa}$ of upset pressure and $20 \mathrm{~s}$ of upset time for $3000 \mathrm{rpm}$ rotational speed. The highest tensile strength, which is $702.15 \mathrm{MPa}$, has resulted in $5.8 \%$ increase over the parent material (AISI 316: $663.53 \mathrm{MPa})$.

Microstructure of the welded specimens was examined by using optic and scanning electron microscope (SEM) as given in Figs. 4 and 5. It is observed that the materials are mixed through a transition in the welding sections. The shape and depth of this mixture change in accordance with the welding parameters.

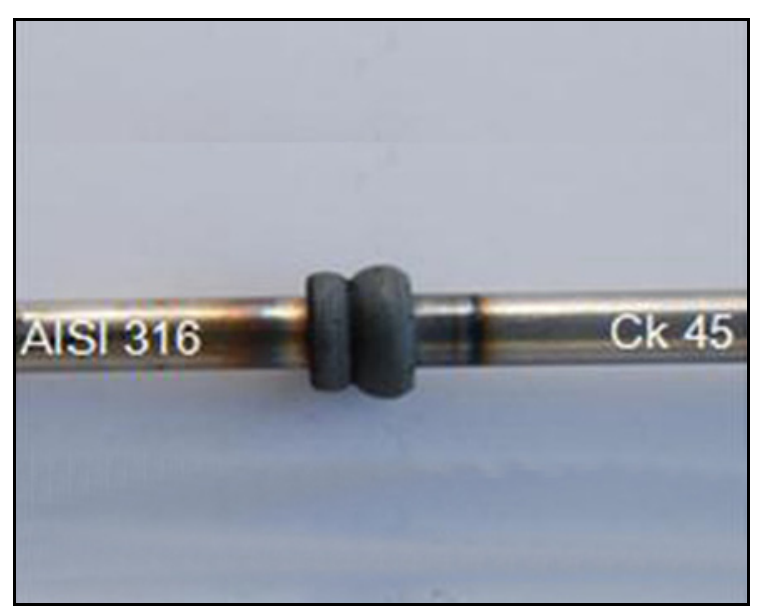

Fig. 2. Macroscopic view of the welded specimen.

\section{Neural network model}

ANNs are computational models, which replicate the function of a biological network, are composed of neurons and are used to solve complex functions in various applications. Neural networks consist of simple synchronous processing elements that are inspired by the biological nerve systems. The basic unit in the 


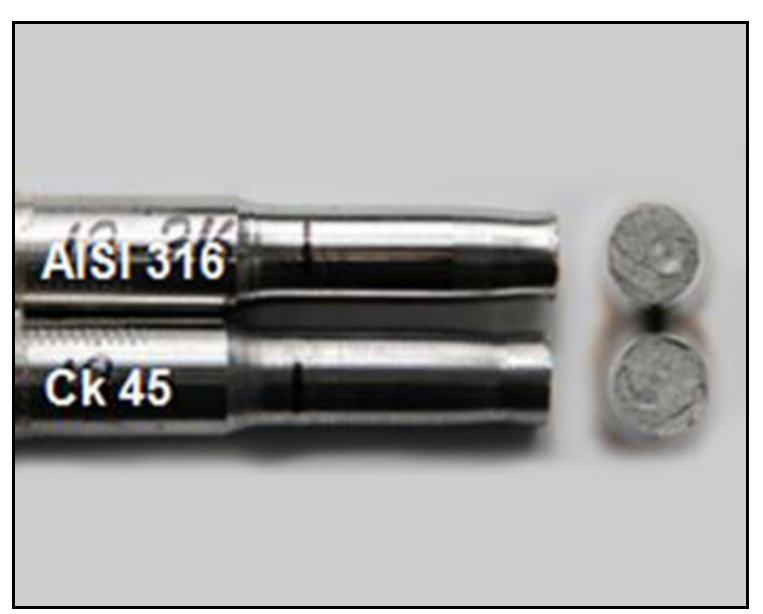

Fig. 3. Macroscopic view of the tensile test.

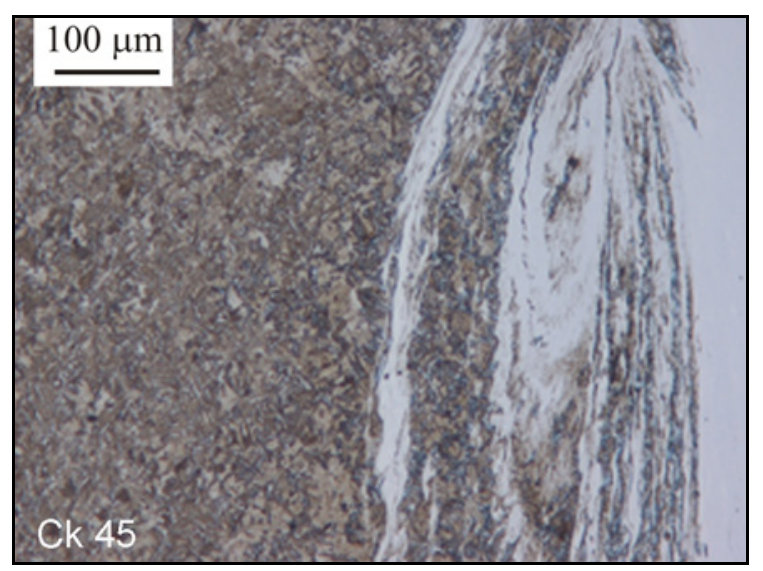

Fig. 4. The optical microstructure of welded specimen.

ANN is the neuron. Neurons are connected by links known as synapses, associated with each synapse there is a weight factor. The system has three layers, which are input, hidden and output layers. The input layer consists of all the input factors. Information from the input layer is then processed in the course of one hidden layer; the following output vector is computed in the final (output) layer $[11,13]$.

In this study, the model that represents the tensile strength of the specimens which are welded by depending on the friction welding parameters is obtained by using the ANN method. Phytia 1.6 application tool was used in all stages of the model development including training and testing the network. Inputs were normalized by employing the relation given below [19]:

$$
I_{\mathrm{n}}=\frac{X-X_{\min }}{X_{\max }-X_{\min }},
$$

where $I_{\mathrm{n}}$ is the normalized value of the parameter $x$ (friction time, friction pressure and upset pressure),
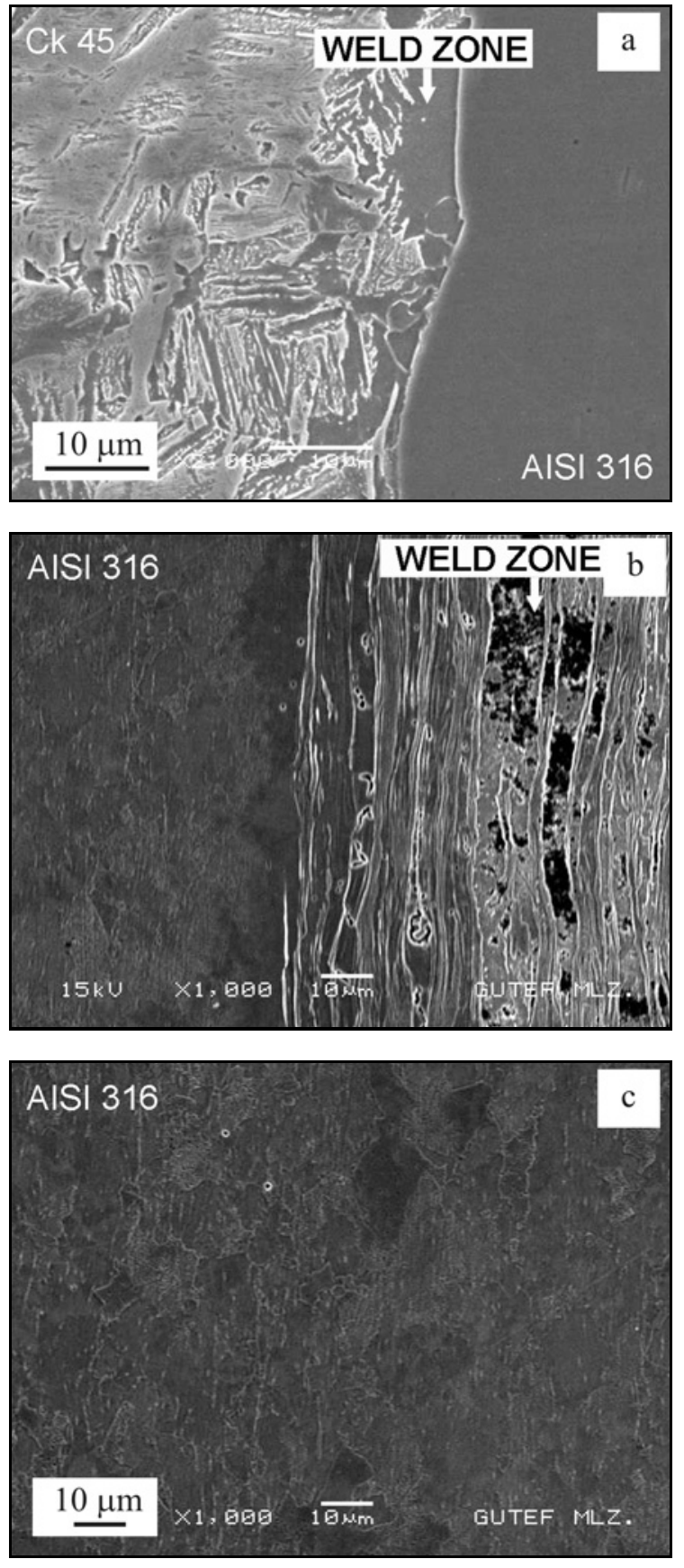

Fig. 5. (a) SEM microstructure of HAZ on Ck 45 steel, as welded, (b) SEM microstructure of weld zone and (c) SEM microstructure of HAZ on AISI 316 steel, as welded.

$X_{\max }$ and $X_{\min }$ are the maximum and minimum values of $x$, respectively. Accordingly each parameter lies in the interval of $[0-1]$.

The coefficient of determination $\left(R^{2}\right)$ is used to measure the relationship between the experimental and predicted output values. The coefficient of deter- 
Table 4. Normalization and weight values

\begin{tabular}{|c|c|c|c|c|}
\hline \multicolumn{5}{|c|}{ Normalization values } \\
\hline \multicolumn{2}{|c|}{$I_{1 i}=\left(t_{\mathrm{f} i}-t_{\mathrm{fmin}}\right) /\left(t_{\mathrm{fmax}}-t_{\mathrm{fmin}}\right)$} & \multicolumn{2}{|c|}{$I_{2 i}=\left(P_{\mathrm{f} i}-P_{\mathrm{fmin}}\right) /\left(t_{\mathrm{fmax}}-P_{\mathrm{fmin}}\right)$} & $I_{3 i}=\left(P_{\mathrm{u} i}-P_{\mathrm{umin}}\right) /\left(t_{\mathrm{umax}}-P_{\mathrm{umin}}\right)$ \\
\hline \multicolumn{5}{|c|}{ Weight values (for the first hidden layer) } \\
\hline Weights & $N_{1}$ & $N_{2}$ & $N_{3}$ & $N_{4}$ \\
\hline$W_{1 j}$ & -0.459658 & -0.441753 & 1.058723 & 1.860639 \\
\hline$W_{2 j}$ & -0.061782 & 0.281935 & -7.557796 & -4.645057 \\
\hline$W_{3 j}$ & -0.300184 & 0.972644 & 2.885313 & 0.797364 \\
\hline
\end{tabular}

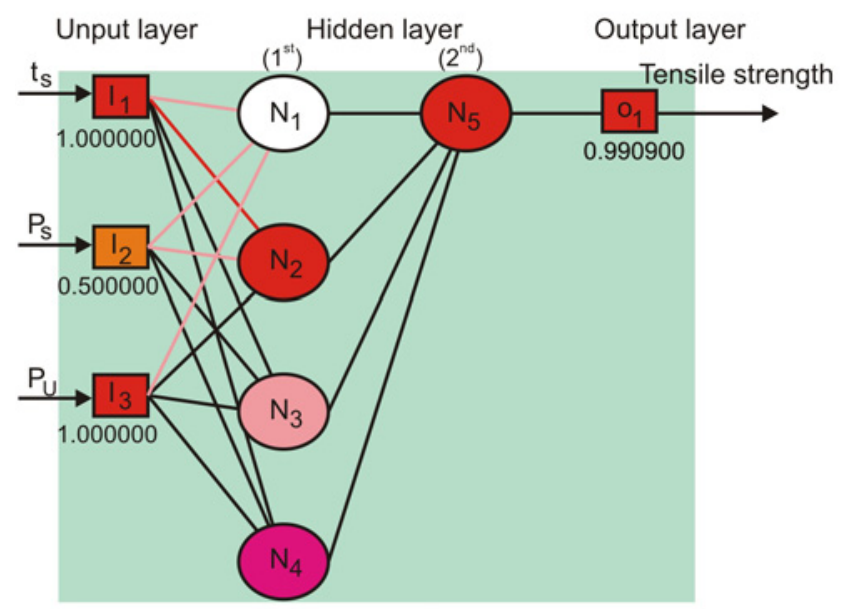

Fig. 6. The structure of the four layered neural network in the present study.

mination used in this study was given as follows [22]:

$$
R^{2}=\left(\frac{n \sum x_{i} y_{i}-\sum x_{i} \sum y_{i}}{\sqrt{n \sum x_{i}^{2}-\left(\sum x_{i}\right)^{2}} \sqrt{\left.n \sum y_{i}^{2}-\left(\sum y_{i}\right)^{2}\right)}}\right)^{2}
$$

where $x_{i}$ is the tensile strength value obtained from the ANN model, $y_{i}$ is the tensile strength value obtained from the experimental study, and $n$ is the number of the experiment.

There are different learning algorithms. A popular algorithm is the backpropagation algorithm, which has different variants $[11,20]$. The model with two hidden layers having four neurons in the first hidden layer and one neuron in the second hidden layer (3-4-1-1 as shown in Fig. 6) is found to be the most suitable network architecture with lowest mean prediction error $(\%)$.

Fermi function was used for transfer and aggregation functions. Aggregation function processes inputs which are related weights so that exact input is obtained. Transfer function defines the process component's output which was detected by aggregation function. The Fermi function used in this study was given as follows:

$$
\begin{gathered}
F=\frac{1}{1+\mathrm{e}^{U}}, \\
U=\sum_{j=0}^{n} W_{j} X_{i}+W_{\mathrm{b} j},
\end{gathered}
$$

where $W_{j}$ is the connection weight value, $X_{i}$ is the normalized value of the inputs, $W_{\mathrm{b}}$ is bias weight value, $n$ is the number of processing elements of the previous hidden layer.

\section{Comparison of ANN and experimental results}

Experimental data are used to train and test the network as given in Tables 2 and 3 . From the total amount of 19 measured results, 14 of them were used to train the network, while the rest of the results were utilized as test data. Inputs for the network were the friction time $\left(t_{\mathrm{s}}\right)$, friction pressure $\left(P_{\mathrm{s}}\right)$ and upset pressure $\left(P_{\mathrm{u}}\right)$, while a single output was the tensile strength.

During the learning process, weight effects on neurons and normalization of input parameters were obtained (Table 4).

Aggregation function, dependent on weight values for each neuron, was determined as:

$$
\begin{aligned}
& F\left(N 1_{i}\right)=1 /(1+ \\
& \left.\exp \left(-4\left(X_{1 i} W_{(1 j)}+X_{2 i} W_{(2 j)}+X_{3 i} W_{(3 j)}-0.5\right)\right)\right) \\
& F\left(N 2_{i}\right)=1 /(1+ \\
& \left.\exp \left(-4\left(X_{1 i} W_{(1 j)}+X_{2 i} W_{(2 j)}+X_{3 i} W_{(3 j)}-0.5\right)\right)\right), \\
& F\left(N 3_{i}\right)=1 /(1+ \\
& \left.\exp \left(-4\left(X_{1 i} W_{(1 j)}+X_{2 i} W_{(2 j)}+X_{3 i} W_{(3 j)}-0.5\right)\right)\right),
\end{aligned}
$$


Table 5. Output weights (for the second hidden layer)

\begin{tabular}{cccc}
\hline$W C_{1}$ & $W C_{2}$ & $W C_{3}$ & $W C_{4}$ \\
\hline-6.987864 & 1.026890 & -6.218046 & 6.807418 \\
\hline
\end{tabular}

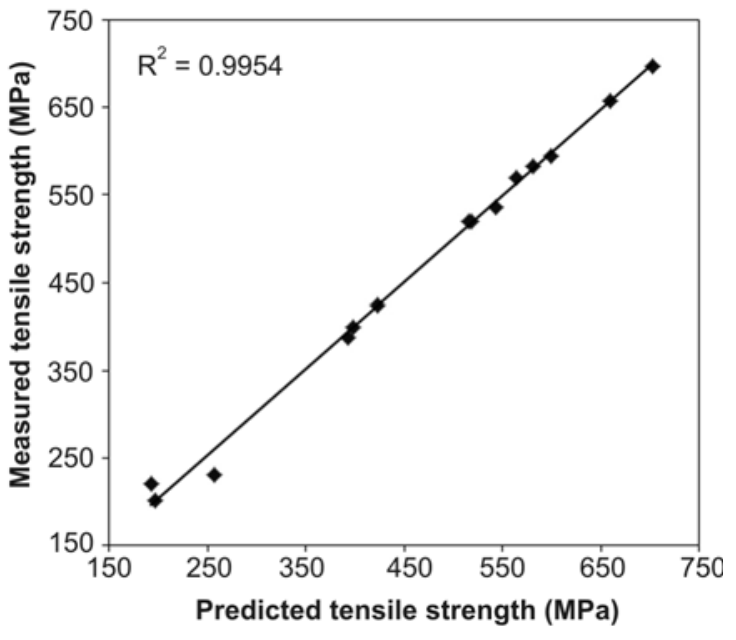

Fig. 7. Comparison of measured and predicted outputs for tensile strength for train data.

$$
\begin{aligned}
& F\left(N 4_{i}\right)=1 /(1+ \\
& \left.\exp \left(-4\left(X_{1 i} W_{(1 j)}+X_{2 i} W_{(2 j)}+X_{3 i} W_{(3 j)}-0.5\right)\right)\right) .
\end{aligned}
$$

In this model, output weights, which defined the process component's output by taking net input determined by aggregation function, were obtained (Table 5).

Depending on the output weights and net inputs ANN model transfer function:

$$
\begin{aligned}
& F\left(N 5_{i}\right)=1 /\left(1+\exp \left(-4\left(N 1_{i} W C_{1}+\right.\right.\right. \\
& \left.\left.\left.N 2_{i} W C_{2}+N 3_{i} W C_{3}+N 4_{i} W C_{4}-0.5\right)\right)\right)
\end{aligned}
$$

where $N$ is the neuron, $W C$ is the output connection weight value, 0.5 is the bias weight value.

The outputs are calculated as follows:

$$
\begin{aligned}
\text { Tensile strength }\left(O_{1}\right)= & \left(N 5_{i}\right)\left(\sigma_{\max }-\sigma_{\min }\right)+ \\
& +\sigma_{\max },(\mathrm{MPa})
\end{aligned}
$$

where $\sigma_{\max }$ is the maximum tensile strength value, and $\sigma_{\min }$ is the minimum tensile strength value.

While the coefficient of determination value of measured and predicted data for tensile strength for train data was $0.9954 \%$ (Fig. 7 ), this value for test data was $0.9462 \%$ (Fig. 8). The tensile strength values calculated from ANN model by using the friction

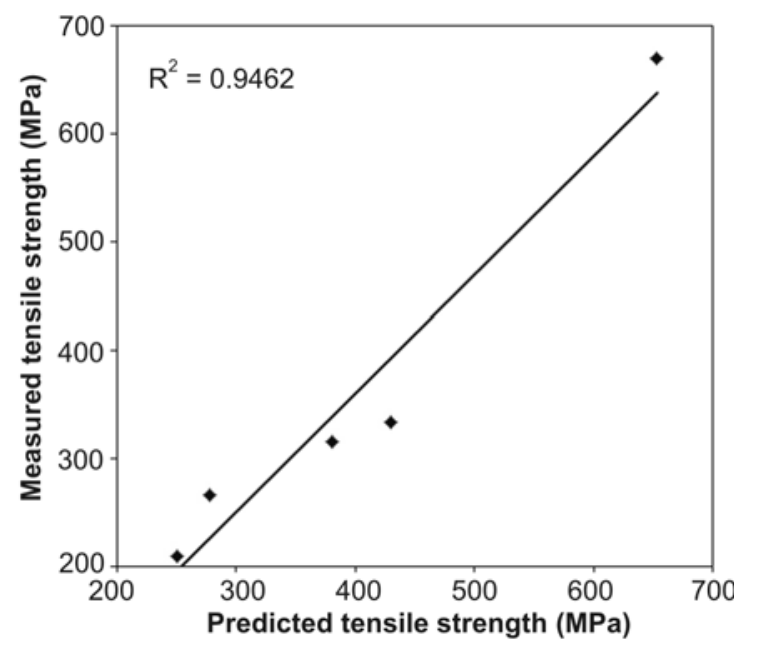

Fig. 8. Comparison of measured and predicted outputs for tensile strength for test data.

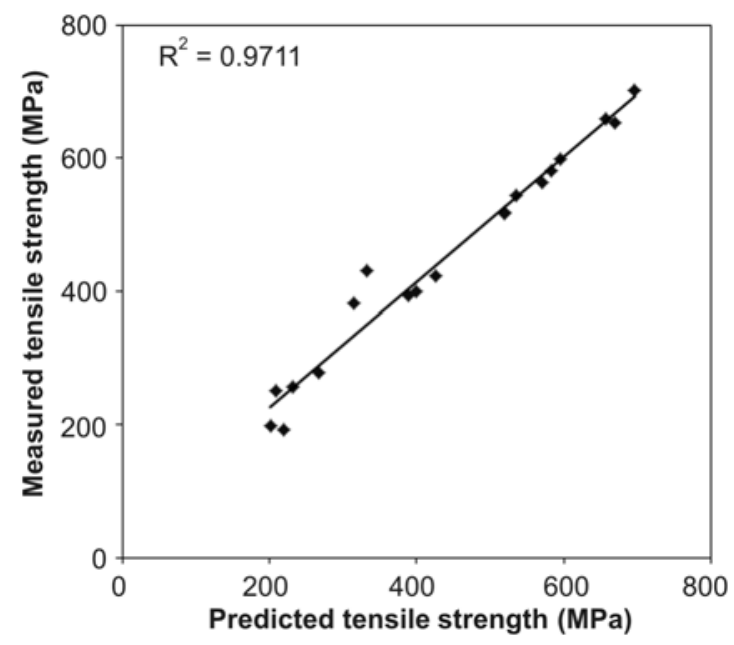

Fig. 9. Comparison of measured and predicted outputs for tensile strength.

welding parameters in Tables 2 and 3 are given in Table 6 . The tensile strength values obtained from ANN model and the results through experimental studies are very close to each other with the coefficient of determination value of $R^{2}=0.9711$ (Fig. 9). Therefore, this neural network model can be used for predicting the outputs of friction welding process with significant accuracy. 
Ta ble 6. Tensile strength results obtained from the ANN model

\begin{tabular}{llllllllllllllllllll}
\hline Specimen No. & 1 & 2 & 3 & 4 & 5 & 6 & 7 & 8 & 9 & 10 & 11 & 12 & 13 & 14 & 15 & 16 & 17 & 18 & 19 \\
\hline
\end{tabular}

Predicted tensile strength (MPa) 425670520657201315536220333519266583697209388570231399595

\section{Conclusions}

The following conclusions can be drawn based on this research:

1. Joint of the AISI 316 austenitic-stainless steel and $\mathrm{Ck} 45$ steel was successfully achieved by the friction welding method. Optimum friction welding parameters were determined in the experimental studies in the joining process of AISI 316 austenitic-stainless steel and Ck 45 steel. Tensile tests applied on welded specimens revealed that friction time, friction pressure and upset pressure, which are friction-welding parameters, were effective on joint strength.

2. The highest tensile strength, which is 702.15 $\mathrm{MPa}$, was resulted $5.8 \%$ more than that of the parent material (AISI 316: $663.53 \mathrm{MPa}$ ).

3. This study shows the possibility of the usage of artificial neural network for the prediction of the tensile strength of welded joint using a friction welding method. A comparison was made between measured and calculated data. The values of tensile strength were measured after experiments, which was very close to the values of tensile strength that were obtained from the developed ANN model $\left(R^{2}=0.9711\right)$.

4. Results showed that the artificial neural network could be used as an alternative way in these systems. The ANN model had a good performance to find similar values of tensile strength that were provided by experimental results.

5. The ANN model was less labor extensive and a reliable method for predicting the friction welding parameters.

\section{References}

[1] Sahin, M.: Mater. Design, 28, 2007, p. 2244. doi:10.1016/i.matdes.2006.05.031

[2] Linnert, G. E.: Welding Metallurgy, Carbon and Alloy Steels. Vol. I, 4th ed. USA: Fundamentals, Published by the American Welding Society, 2003, p. 444.

[3] Welding Handbook, Welding Processes. Vol. 2, 8th ed. Miami: Copyright by the American Welding Society Inc. 1997, p. 761 .

[4] Celik, S., Ersozlu, I..: Mater. Design, 30, 2009, p. 970. doi:10.1016/j.matdes.2008.06.070
[5] Bramfitt, B. L., Benscoter, A. O.: Metallographer's Guide Practices and Procedures for Irons and Steels. Materials Park, ASM International 2002.

[6] Welding: Design, Procedures and Inspection Technical Manual TM 5-805-7. Washington, Department of the Army 1985.

[7] Celik, S., Dinc, D., Yaman, R., Ay, I.: Prakt. Metallogr., 47, 2010, p. 188. doi:10.3139/147.110040

[8] Özdemir, N., Sarsilmaz, F., Hasçalik, A.: Mater. Design, 28, 2007, p. 301. doi:10.1016/j.matdes.2005.06.011.

[9] Arivazhagan, N., Singh, S., Prakash, S., Reddy, G. M.: Mater. Design, 32, 2011, p. 3036. doi:10.1016/i.matdes.2011.01.037.

[10] Domblesky, J., Kraft, F. F., Druecke, B., Sims, B.: J. Mater. Process. Tech., 171, 2006, p. 141. doi:10.1016/i.jmatprotec2005.06.066

[11] Okuyucu, H., Kurt, A., Arcaklioglu, E.: Mater. Design, 28, 2007, p. 78. doi:10.1016/i.matdes.2005.06.003

[12] Yousif, Y. K., Daws, K. M., Kazem, B. I., Jordan, J.: Mechanical and Industrial Engineering, 2, 2008, p. 151.

[13] Lakshminarayanan, A. K., Balasubramanian, V.: Transactions of Nonferrous Metals Society of China, 19, 2009, p. 9. doi:10.1016/S1003-6326(08)60096-5

[14] Sathiya, P., Aravindan, S., Noorul, A. H., Panneerselvam, K.: Indian J. Eng. and Mater. Sci., 13, 2006, p. 37.

[15] Acherjee, B., Mondal, S., Tudu, B., Misra, D.: Applied Soft Computing, 11, 2011, p. 2548. doi:10.1016/i.asoc.2010.10.005

[16] Ozerdem, M. S., Kolukisa, S.: J. Mater. Process. Tech., 199, 2008, p. 437. doi:10.1016/j.jmatprotec.2007.06.071

[17] Rao, V. B. C.: Neural Networks and Fuzzy Logic. Foster City, IDG Books Worldwide, Inc. 1995.

[18] Sha, W., Edwards, K. L.: Mater. Design, 28, 2007, p. 1747. doi:10.1016/i.matdes.2007.02.009

[19] Mandal, S., Sivaprasad, P. V., Venugopal, S., Murthy, K. P. N.: Applied Soft Computing, 9, 2009, p. 237. doi:10.1016/j.asoc.2008.03.016

[20] Kurt, A.: Expert Systems with Applications, 36, 2009, p. 9645. doi:10.1016/j.eswa.2008.12.054

[21] Celik, S., Ersozlu, I.: High Temp. Mater. Proc., 33, 2014, p. 161. doi:10.1515/htmp-2013-0042

[22] Walpole, R. E., Myers, R. H., Myers, S. L., Ye, K.: Probability and Statistics for Engineers and Scientists. New York, Prentice Hall 2002. 